\title{
Effects of prone positioning during extracorporeal membrane oxygenation for refractory respiratory failure: a systematic review
}

\author{
Chaofan Liu ${ }^{1} \cdot$ Yanzhu Chen ${ }^{1} \cdot$ Yulan Chen $^{1} \cdot$ Bin Chen $^{1} \cdot$ Guojin Xie $^{1} \cdot$ Yi Chen $^{1,2}$ (D)
}

Accepted: 18 June 2021 / Published online: 15 July 2021

(C) The Author(s), under exclusive licence to Springer Nature Switzerland AG 2021

\begin{abstract}
As more and more studies have shown that venovenous extracorporeal membrane oxygenation (VV-ECMO) improves oxygenation and prognosis of critical patients, VV-ECMO has been frequently used in critical patients for severe acute respiratory distress syndrome (ARDS). Prone positioning (PP) is a postural therapy for ARDS, which permits for better ventilation/perfusion ratio (V/Q) matching, improvement of hypoxemia. Some articles revealed that performing PP during ECMO for refractory respiratory failure is feasible; however, the results obtained were controversial. Therefore, we performed a systematic review to further assess the effects of PP during ECMO for refractory respiratory failure. Six studies with 465 subjects were enrolled. Four articles examined changes of $\mathrm{PaO} 2 / \mathrm{FiO} 2$ ratio after PP during VV-ECMO; PaO2/FiO2 ratio improved from 18.5 to 62 $\mathrm{mmHg}$. Our analysis inferred that the PP-ECMO group did not have a significant advantage in survival at discharge (odds risk $1.42,95 \%$ confidence interval $0.92-2.18 ; \mathrm{p}=0.11$ ) compared with the ECMO group. We found that the PP-ECMO group had a significantly longer duration than the ECMO group (MD 5.37, 95\% CI 4.19-6.54, $\mathrm{I}^{2}=67 \%, \mathrm{P}<.00001$ ). ICU length of stay in the PP-ECMO group was significantly longer than the ECMO group (MD 7.29, 95\% CI 4.06-10.52, $\mathrm{I}^{2}=64 \%, \mathrm{P}<.00001$ ). No unplanned extubation of ECMO was recorded. In conclusion, our review found that performing PP during ECMO for refractory respiratory failure is safe and $\mathrm{PP}$ can improve the $\mathrm{PaO} 2 / \mathrm{FiO} 2$ ratio, which is in line with the length of PP performed.
\end{abstract}

Keywords Extracorporeal membrane oxygenation $\cdot$ Prone positioning $\cdot$ Acute respiratory distress syndrome $\cdot$ Refractory respiratory failure

\section{Introduction}

Extracorporeal membrane oxygenation (ECMO) provides gas exchange as well as cardiac support thereby allowing for recovery from existing lung and/or cardiac disease [1]. Venovenous ECMO (VV-ECMO) is one of the most common types. More and more studies have proved that VV-ECMO improves the oxygenation and prognosis of critical patients.

\footnotetext{
Chaofan Liu and Yanzhu Chen are co-first authors.

This article is part of the Topical Collection on Covid-19

Yi Chen

chenyi icu@163.com

1 Department of Intensive Care Unit, Binhaiwan Central Hospital of Dongguan, Guangdong Province, Dongguan City, China

2 Dongguan City, China
}

VV-ECMO is recommended in adults suffering from severe acute respiratory distress syndrome (ARDS) [2]. Prone positioning (PP) is a postural therapy influencing the patient's oxygenation by improving the balance between lung ventilation and perfusion, recruiting dependent lung tissue, and promoting drainage of pulmonary secretions [3]. Thus, PP permits for better V/Q matching, improving hypoxemia and decreasing ventilator-induced lung injury [4]. To date, PP is probably the only therapy modality identified to improve survival for severe ARDS [5]. PP is also feasible and effective in rapidly ameliorating blood oxygenation in awake patients with COVID-19-related pneumonia requiring oxygen supplementation [6]. However, guidelines and consensus statements on PP are still lacking. And, there are few studies focusing on the potential of the application of PP during VV-ECMO.

To address this issue, we systematically reviewed previous studies on the effects of PP during ECMO for refractory respiratory failure, aiming to provide existing pieces of evidence 
and some advice for clinicians and scholars when tackling refractory respiratory failure with PP during ECMO.

\section{Methods}

\section{Search strategies}

We performed a systematic and comprehensive search in PubMed, Medline, Web of Science, CNKI Database, and Wanfang Database (two main databases in China) from January 2000 to October 2020. The following search terms were used: extracorporeal membrane oxygenation, prone positioning, acute respiratory distress syndrome, refractory respiratory failure (Applied English and Chinese restriction).

\section{Inclusion and exclusion criteria}

Studies on PP applied during VV-ECMO for respiratory failure in critical adult patients were included. The excluded studies criteria were as follows: (1) the subjects were less than 18 years old; (2) the subjects received VA-ECMO or VAVECMO; (3) reviews or case reports.

\section{Study selection}

Two independent reviewers screened the titles and abstracts wisely on the databases above and include studies meeting the inclusion criteria. The divergence between them was evaluated by a third reviewer.

\section{Data extraction and analysis}

Two independent reviewers extracted demanding information of each included study, including article types, publication year, country, baseline characteristics, change of $\mathrm{PaO} 2 / \mathrm{FiO} 2$, and clinical outcomes. Besides, the divergence between the two reviewers was evaluated by the third reviewer. Data extracted was analyzed using RevMan version 5.4 which was provided by Cochrane.

\section{Results}

Six articles fulfilled the inclusion criteria, which were all retrospective studies. A total of 465 subjects were included in this review, 212 subjects (45.6\%) received VV-ECMO and PP therapy, and the rest (54.4\%) received VV-ECMO only. Clinical characteristics were showed in Table 1.

\section{Improvement in $\mathrm{PaO2} / \mathrm{FiO2}$ ratio}

Four articles examinated changes of $\mathrm{PaO} 2 / \mathrm{FiO} 2$ ratio after $\mathrm{PP}$ during VV-ECMO, reporting improvement in $\mathrm{PaO} 2 / \mathrm{FiO} 2$ ratio after $\mathrm{PP}$ in 465 subjects $[3,5,7,8]$. $\mathrm{PaO} 2 / \mathrm{FiO} 2$ ratio improved from 18.5 to $62 \mathrm{mmHg}$. In Antoine Kimmoun's study, prolonged $\mathrm{PP}(24 \mathrm{~h})$ improved $\mathrm{PaO} 2 / \mathrm{FiO} 2$ ratio by $62 \mathrm{mmHg}$ [7]. In Lucchini A.' study, PP lasting for $8 \mathrm{~h}$ improved $\mathrm{PaO} 2 /$ $\mathrm{FiO} 2$ ratio by $18.5 \mathrm{mmHg}$ [3]. The length of the PP procedure lasting for another two studies was $12 \mathrm{~h}$ and $15 \mathrm{~h}$, respectively $[5,8]$.

\section{Clinical outcomes on survival}

The overall survival rate of the 6 studies enrolled was $53.1 \%$. One hundred thirty-one patients $(61.8 \%)$ in the ECMO-PP group survived, while 116 patients $(45.8 \%)$ in the ECMO group subjects did. Two studies reported a comparison of survival at discharge between PP-ECMO and ECMO groups $[5,10]$. The PP-ECMO group did not show significant advantage in discharged survival compared with ECMO group (odds risk 1.42, 95\% confidence interval 0.92-2.18; $\mathrm{p}=$ 0.11 ) (Figure 1). There was no evidence of heterogeneity across studies $\left(p=0.28, I^{2}=14 \%\right)$. Notable, a study reported that earlier PP $(<17 \mathrm{~h})$ showed a significant survival benefit compared with later or no PP (82\% vs. 33\%) [10].

\section{ECMO duration and ICU length of stay}

Two studies reported comparisons of ECMO duration and ICU length of stay between PP-ECMO and ECMO groups $[5,10]$. In this review, we found that the PP-ECMO group had a significantly longer duration than the ECMO group (MD 5.37, 95\% CI 4.19-6.54, $\mathrm{I}^{2}=67 \%, \mathrm{P}<.00001$ ) (Figure 2). ICU length of stay in the PP-ECMO group was significantly longer than the ECMO group (MD 7.29, 95\% CI $4.06-10.52, \mathrm{I}^{2}=64 \%, \mathrm{P}<.00001$ ) (Figure 3 ).

\section{Complications of PP during ECMO}

No dislodgment of ECMO cannules when applying PP was reported $[3,5,7,8,10,11]$. Minor reversible complications were reported in $6 \%$ of subjects by Giani et al. [5]. The reversible complications were consist of desaturation (2.5\%), bleeding $(1.2 \%)$, decrease of blood flow $(1.2 \%)$, hemodynamic instability $(0.6 \%)$, increased $\mathrm{PaCO} 2(0.3 \%)$, thigh swelling $(0.3 \%)$, face swelling $(0.3 \%)$, and vomiting $(0.3 \%)$ [5]. Antoine Kimmoun et al. reported one membrane thrombosis and one drop in ECMO blood flow in the study [7]. One pneumothorax that occurred during PP was reported in one study [8]. No displacement of vascular lines, ECMO cannula, endotracheal tube, or chest tubes was observed in 6 studies [3, $5,7,8,10,11]$. 
Table 1 Characteristics of 6 included studies

\begin{tabular}{|c|c|c|c|c|c|c|}
\hline Study (year) & Country & Study type & Sample size & PP-ECMO group & ECMO group & The length of PP procedure \\
\hline Antoine Kimmoun (2015) & France & Retrospective study & $\mathrm{N}=17$ & $\mathrm{~N}=17$ & $\mathrm{~N}=0$ & $24 \mathrm{~h}$ \\
\hline Jonathan Rilinger (2020) & Germany & Retrospective study & $\mathrm{N}=158$ & $\mathrm{~N}=38$ & $\mathrm{~N}=120$ & Not mentioned \\
\hline Marco Giani (2020) & Italy & Retrospective study & $\mathrm{N}=240$ & $\mathrm{~N}=107$ & $\mathrm{~N}=133$ & $15 \mathrm{~h}$ \\
\hline Alberto Lucchini (2018) & Sweden & Retrospective study & $\mathrm{N}=14$ & $\mathrm{~N}=14$ & $\mathrm{~N}=0$ & $8 \mathrm{~h}$ \\
\hline Guillaume Franchineau (2020) & France & Retrospective study & $\mathrm{N}=21$ & $\mathrm{~N}=21$ & $\mathrm{~N}=0$ & Not mentioned \\
\hline C. Guervilly (2014) & France & Retrospective study & $N=15$ & $\mathrm{~N}=15$ & $\mathrm{~N}=0$ & $12 \mathrm{~h}$ \\
\hline
\end{tabular}

\section{Discussion}

ARDS remains a clinically relevant disease-causing acute inflammation affecting the lung's gas exchange surface, the alveolar-capillary membrane $[2,12]$. ARDS results in high morbidity and mortality, which is about $24 \%$ in patients with mild ARDS, sharply rising to $48 \%$ in the group of patients with the most severe respiratory failure $[2,13]$. Conventional treatment modalities for ARDS include supportive care by prone positioning, lung-protective ventilation, nitric oxide inhalation, administration of intravenous steroids, and a causal anti-infective therapy [14]. Treatments with VV-ECMO have been rapidly increasing since the last decades [15]. In the treatment of ARDS, VV-ECMO is a meanwhile established therapeutic approach despite ongoing discussion regarding evidence $[14,15]$. In the management of ARDS, VV-ECMO enhances gas exchange and may mitigate ventilator-induced lung injury. Although previous studies have failed to show a prominent benefit in mortality for VV-ECMO application in ARDS, they suggested potential advantages in clinical symptoms and mortality [16-19].

$\mathrm{PP}$ has been used for many years and is now recommended for patients with severe or moderate-to-severe ARDS. Up to now, PP for severe ARDS is probably the single treatment associated with the greater survival advantage in critically ill patients [4]. The APRONET analysis, screening in 141 ICUs from 20 countries, revealed that PP was applied in $32.9 \%$ of patients with severe ARDS, which was associated with low complication rates, a significant increase in oxygenation, and a significant decrease in driving pressure [20]. PP can improve oxygenation of ARDS by increasing the quantity of tissue open to ventilation and perfusion during the respiratory cycle and the homogeneous ventilation [21]. It redistributes mechanical ventilation load, reduces tidal hyperinflation, and homogenizes the distribution of transpulmonary pressure, thus mitigating the risk of VILI from alveolar overstretching and cyclic atelectasis [5]. A fraction of critical patients with COVID-19-related pneumonia experienced rapid deterioration of lung function causing severe hypoxemia; some centers incipiently promote $\mathrm{PP}$ in spontaneous breathing patients even prior to endotracheal intubation and mechanical ventilation [22]. In case of refractory respiratory failure, VV-ECMO support may be considered when lung-protective mechanical ventilation is not able to prevent hypoxia or hypercapnia [10]. The combination of strategies (VV-ECMO and PP) had been proved to improve the overall survival rate in the previous study [6]. But, there are few studies about the potential of application of PP during VV-ECMO and most of them were small and single-center retrospective studies. In this article, we enrolled 6 retrospective studies, containing 465 patients. Two hundred twelve subjects received PP therapy during ECMO; the rest received VV-ECMO only. We aimed to explore the effects of PP during VV-ECMO for refractory respiratory failure.

According to the mechanisms of PP, the outcome improvements of PP are complex, including gas exchange, recruitment, and protection of lung tissue [21]. Oxygenation is the most common criteria used to assess PP. PP can improve oxygenation of ARDS as a result of a reduction in shunt and ventilation-perfusion heterogeneity [21]. Different studies showed different increasements of the $\mathrm{PaO} 2 / \mathrm{FiO} 2$ ratio. According to the 4 studies enrolled in our study, the $\mathrm{PaO} 2 /$ FiO2 ratio improved mostly when PP lasted for 24 h [7], despite ameliorating effect was observed at first $8 \mathrm{~h}$ since PP

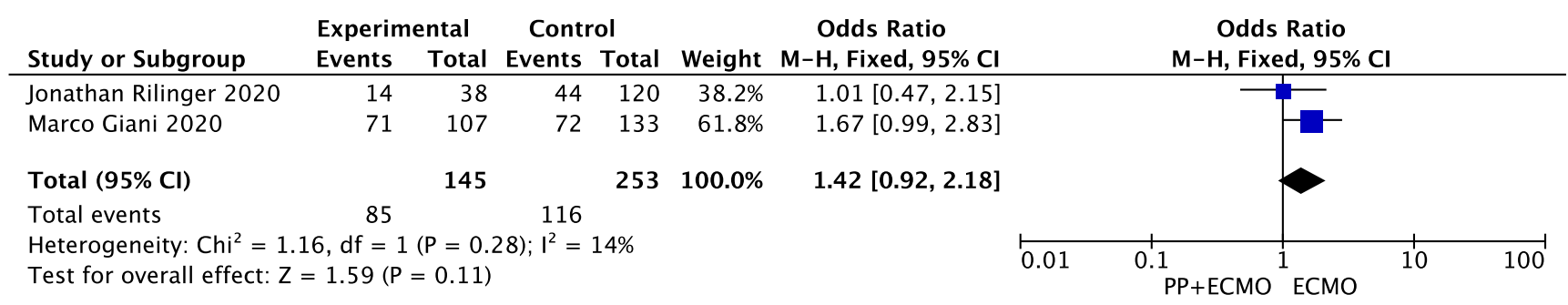

Fig. 1 Forest plot of survival at discharge between PP-ECMO and ECMO groups 


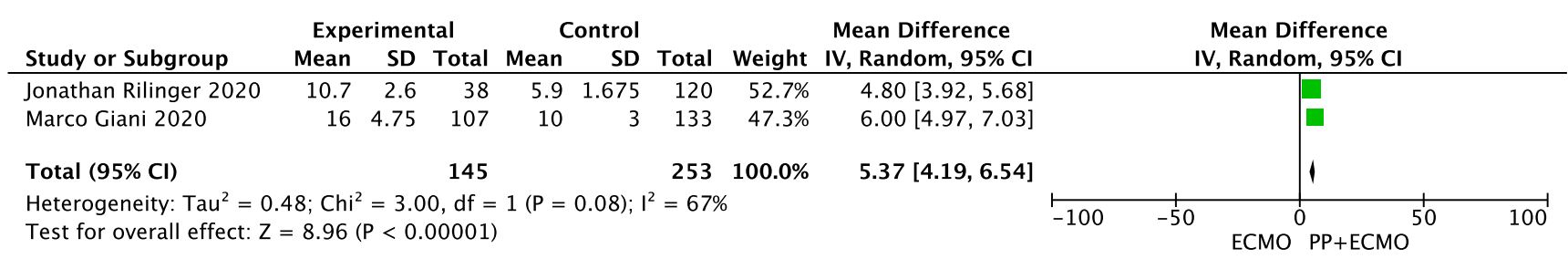

Fig. 2 Forest plot of ECMO duration between PP-ECMO and ECMO groups

was practiced [3]. The improvement of the $\mathrm{PaO} 2 / \mathrm{FiO} 2$ ratio seemingly has a positive correlation with the duration of the PP procedure, which is consistent with previous research suggesting that the longer the duration PP was performed, the greater the benefits would be $[6,23,24]$. Clinical trial evidence suggests that to achieve improved survival with prone positioning, a long duration of prone positioning ( $>16 \mathrm{~h} /$ day) is advisable [25]. The 2019 Faculty of Intensive Care Medicine and Intensive Care Society (FICM/ICS) Guidelines for the management of ARDS recommended over $12 \mathrm{~h}$ of PP for ARDS basing on the outcome of subgroup analysis [2]. Considering the possible difficulties for management of PP during ECMO such as hemodynamic instability, complicated practice, we propose that when it comes to refractory respiratory failure which could not be ameliorated by VV-ECMO therapy and no contraindication is existing, PP should be performed and the duration of PP should be as long as possible.

The impact of PP on the mortality of ARDS has been studied for decades. The mortality benefit of PP did not be confirmed until several types of research focusing on the subgroup analysis were documented recently. The 2019 FICM/ ICS Guidelines for the management of ARDS point out that PP can significantly reduce the mortality of ARDS, but the evidence quality is low because of the bias, serious inconsistency. PROSEVA trial revealed that PP reduced the 28-day mortality of moderate-severe ARDS (PP vs. Supine position, $16 \%$ vs. $33 \%$, RR $0.39,95 \%$ CI $0.25-0.63$ ) [26]. Owing to only two of 6 studies enrolled in our article investigated the difference in survival at discharge between the PP plus ECMO and ECMO groups $[5,10]$. The inpatient survivals did not show a statistical distinction between PP plus ECMO and ECMO groups (85/145 (58.6\%) vs $116 / 253$ (45.8\%); OR 1.42 (95\% CI 0.92-2.18); $\left.I^{2}=14 \% ; p=0.28\right)$. It seems that $\mathrm{PP}$ is preferred to promote the survival of refractory respiratory failure after VV-ECMO; however, given that the number of cases in both groups is relatively small, no significant difference can be observed. Urgently, a further large clinical trial is required to carry out for verification. As for subgroup analysis, only one study enrolled performed subgroup analysis. Jonathan Rilinger et al. examined the impact of timing for $\mathrm{PP}$, and they found that early $\mathrm{PP}(<17 \mathrm{~h})$ in contrast to later or no PP showed a significant survival benefit [10]. Early initiation of PP after ECMO cannulation was strongly associated with improved survival, which is consistent with Claude Guérin's findings [10]. In Claude Guérin's research, the results prompted that early application (less than $36 \mathrm{~h}$ ) of constant PP therapy significantly decreased 28-day and 90-day mortality, but the incidence of complications did not differ significantly compared with supine group [9]. Therefore, it seems meaningful to initiate the combination of PP and ECMO for refractory respiratory failure which is ineffective to usual care. As the enrolled studies are all retrospective, they differed at the timing of initiation and ending of PP, assessment of PP, and practice of PP; we could not obtain the integral information and extract enough data for pooled analysis or further subgroup analysis. To date, consensuses of predictors of PP response, the timing for initiation of PP, and practice of PP after ECMO for refractory respiratory failure are still lacking; further study is needed.

Few studies have examined the impact of PP on ICU length of stay. Two meta-analyses reported that ICU length of stay is not different between PP and supine position; however, the enrolled studies are all performed before 2008 and considered to be obvious heterogeneity $[27,28]$. Among the studies enrolled in the 2 meta-analyses, Mancebo J.'s team performed a multicenter trial of prolonged PP $(17 \mathrm{~h})$ in severe ARDS, and they found that PP did not markedly influence the ICU length of stay [29]. Two studies enrolled in our article reported the comparisons of ECMO duration and ICU length of stay between PP-ECMO and ECMO groups [5, 10]. The results showed that the PP-ECMO group dramatically increased the duration of ECMO (MD 5.37, 95\% CI 4.19-6.54, $\mathrm{I}^{2}=67 \%$, P $<.00001$ ), the length of MV, and the stay of ICU (MD7.29,

\begin{tabular}{|c|c|c|c|c|c|c|c|c|c|c|c|c|}
\hline \multirow[b]{2}{*}{ Study or Subgroup } & \multicolumn{3}{|c|}{ Experimental } & \multicolumn{3}{|c|}{ Control } & \multirow[b]{2}{*}{ Weight } & \multirow{2}{*}{$\begin{array}{l}\text { Mean Difference } \\
\text { IV, Random, } 95 \% \mathrm{CI}\end{array}$} & \multirow{2}{*}{\multicolumn{4}{|c|}{$\begin{array}{c}\text { Mean Difference } \\
\text { IV, Random, } 95 \% \mathrm{CI}\end{array}$}} \\
\hline & Mean & SD & Total & Mean & SD & Total & & & & & & \\
\hline Jonathan Rilinger 2020 & 18 & 4.775 & 38 & 12.3 & 3.225 & 120 & $51.9 \%$ & $5.70[4.08,7.32]$ & & & $\square$ & \\
\hline Marco Giani 2020 & 35 & 7.25 & 107 & 26 & 9 & 133 & $48.1 \%$ & $9.00[6.94,11.06]$ & & & $\mathbf{a}$ & \\
\hline Total $(95 \% \mathrm{Cl})$ & & & 145 & & & 253 & $100.0 \%$ & $7.29[4.06,10.52]$ & & & 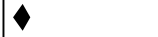 & \\
\hline $\begin{array}{l}\text { Heterogeneity: } \mathrm{Tau}^{2}=4 \\
\text { Test for overall effect: } Z\end{array}$ & $\begin{array}{l}5 ; \mathrm{Chi}^{2} \\
=4.42\end{array}$ & $\begin{array}{l}=6.09 \\
(P<0.0\end{array}$ & $\begin{array}{l}\mathrm{df}= \\
0001)\end{array}$ & $1(P=$ & $1)$; & $=84 \%$ & & & -100 & -50 & $P P+E C M O$ & 100 \\
\hline
\end{tabular}

Fig. 3 Forest plot of ICU length of stay between PP-ECMO and ECMO groups 
95\% CI 4.06-10.52, $\left.\mathrm{I}^{2}=64 \%, \mathrm{P}<.00001\right)$, compared with the ECMO group. That means the reason for no significant differences in the baseline of clinical characteristics (SOFA score, APACHE II score, andRESP score) between the two groups was not found. [10]. But, in another study, the SOFA score was higher in the ECMO group $(\mathrm{p}<0.001)$ [5]. No obvious relation of ECMO duration or ICU stay length and severity of disease could be found. The PP + ECMO combination strategy is regarded as the salvage treatment for the patients who had a poor effect in ECMO treatment, and the PP measure was initiated in some patients when ECMO treatment was close to failure. The grading system (SOFA score, APACHE II score, and RESP score) may be insufficient in the evaluation of severe ARDS, that is, patients with $\mathrm{PaO} / \mathrm{FiO} 2$ ratio of $<100 \mathrm{mmHg}$ cannot be individual in SOFA score. In that context, the SOFA score alone may not be consist with the severity of hypoxia. Besides, it would need more sedatives and neuromuscular blocking agents to maintain a deeper sedation level during the PP procedure, which means reducing the rate of spontaneous breathing or even no spontaneous breathing. Sequentially, the subjects need more time (longer ECMO duration and ICU length of stay) to recover. Anna Coppo et al. found that PP in awake, spontaneous breathing patients are feasible in most critical care patients with COVID-19related pneumonia [6]. Awake PP may alleviate the respiratory deterioration in patients with COVID-19, easing the strain placed on intensive care services around the world [30]. Maybe PP during ECMO in awake, spontaneously breathing patients with COVID19-related pneumonia could improve survival and prognosis; however, it will need more pieces of evidence to assess the value of awake PP during ECMO. Confirming for timing and indication of the PP-ECMO combination in the ARDS treatment strategy may be critical to reverse the disadvantage in ECMO treatment for refractory respiratory failure.

It is prone for us to consider the complications of PP during VV-ECMO, the complications that include, but are not limited to, tubes dislodgement (endotracheal tubes, central venous catheters, and urinary catheters), hemodynamic variations (cardiac rate, mean arterial pressure, dosage of vasopressor), bleeding at the cannulas insertion sites, facial region injuries, and increased pressure sores [21]. Dislodgment of ECMO cannulas is regarded as the severe adverse event related to $\mathrm{PP}$, because it could cause result in blue ruin. PP is a complex and coordinated work, asking for physicians and nurses global cooperation. Alberto Lucchini recommends a total of six staff involved at least four operators performing the turning of patient, one looking after the ECMO circuit, and one for the management and protection of the endotracheal tube [3]. It is suggested to make full preparation at the bedside in case of emergency re-intubation. No dislodgment of ECMO cannulas or endotracheal tube was recorded in the studies enrolled. Likewise, a systematic review, in regard to complications of PP during ECMO, enrolled 7 studies reported that no dislodgment of ECMO cannulas in the process [31].
Desaturation was recognized as the most common complication in a study with an incidence rate of $2.55 \%$. A system review revealed that $57 \%$ of patients nursed in the prone position developed pressure sores and precautionary measures including skin assessment and care, offloading and pressure redistribution, and dressings for prevention [32]. Most of the complications of prone positioning in the studies during ECMO were reversible. Hence, it is safe to perform PP during ECMO for refractory respiratory failure for an experienced ICU team.

\section{Limitations}

Our study has several limitations. First, the studies enrolled in our article are retrospective, with obvious heterogeneity in the procedure of $\mathrm{PP}$, inducing inevitable information bias. Besides, the sample size is small, making the evidence quantity low. Furthermore, we cannot extract enough data for subgroup analysis. Prospective, randomized control trials on the combination of strategies of ECMO and PP are needed for further research.

\section{Conclusion}

In this article, we enroll 6 studies with 465 subjects to investigate the impact of PP on refractory respiratory failure after VV-ECMO. It is rational to deduce that performing PP during ECMO for refractory respiratory failure is safe and PP can improve the $\mathrm{PaO} 2 / \mathrm{FiO} 2$ ratio, which is in synchrony with the length of PP. Maybe it can improve survival by initiating PP earlier during ECMO for refractory respiratory failure, which is still requiring more studies to confirm. The PPECMO group had a significantly longer duration of ECMO, longer duration of $\mathrm{MV}$, and longer stay of ICU, compared with the ECMO group; the reasons for that are still not clearly explicated.

Abbreviations VV-ECMO, venovenous extracorporeal membrane oxygenation; ARDS, acute respiratory distress syndrome; PP, prone positioning; V/Q, ventilation/perfusion ratio; COVID-19, coronavirus disease 2019; ICU, intensive care unit; $\mathrm{PaO} 2$, partial pressure of arterial oxygen; $\mathrm{FiO} 2$, fraction of inspired oxygen; MV, mechanical ventilation

Author contributions Chaofan, Liu and Yanzhu, Chen contributed to the literature reviewing, writing, and manuscript editing. All authors read and approved the final manuscript.

Funding This work was supported by the Evaluation of Prone positioning in the treatment of severe ARDS (Hospital project of Binhaiwan Central Hospital of Dongguan, grant No. 2021004). 
Data availability Not applicable.

\section{Declarations}

Ethics approval and consent to participate Not applicable.

Consent for publication Not applicable.

\section{References}

1. Extracorporeal Life Support Organization. ELSO Guidelines for ECMO Centers. Accessed Mar 2014. https://www.elso.org/ $\mathrm{P}$ or t a $1 \mathrm{~s} / 0 / \mathrm{I} \mathrm{G} \mathrm{D/A} \mathrm{r} \mathrm{c} \mathrm{hive/File} \mathrm{Man} \mathrm{a} \mathrm{g} \mathrm{e} \mathrm{r} \mathrm{/}$ faf3f6a3c7cusersshyerdocumentselsoguidelinesecmocentersv1.8.

2. Griffiths MJD, McAuley DF, Perkins GD, Barrett N, Blackwood B, Boyle A, et al. Guidelines on the management of acute respiratory distress syndrome. BMJ Open Respir Res. 2019;6(1):e000420. https://doi.org/10.1136/bmjresp-2019-000420.

3. Lucchini A, De Felippis C, Pelucchi G, Grasselli G, Patroniti N, Castagna L, et al. Application of prone position in hypoxaemic patients supported by veno-venous ECMO. Intensive Crit Care Nurs. 2018;48:61-8. https://doi.org/10.1016/j.iccn.2018.04.002.

4. Gordon A, Rabold E, Thirumala R, Husain AA, Patel S, Cheema T, et al. Prone positioning in ARDS. Crit Care Nurs Q. 2019;42(4): 371-5. https://doi.org/10.1097/CNQ.0000000000000277.

5. Giani M, Martucci G, Madotto F, Belliato M, Fanelli V, Garofalo E, et al. Prone positioning during venovenous extracorporeal membrane oxygenation in acute respiratory distress syndrome: a multicentre cohort Study and Propensity-matched Analysis. Ann Am Thorac Soc. 2020;18:495-501. https://doi.org/10.1513/ AnnalsATS.202006-625OC.

6. Coppo A, Bellani G, Winterton D, Di Pierro M, Soria A, Faverio P, et al. Feasibility and physiological effects of prone positioning in non-intubated patients with acute respiratory failure due to COVID19 (PRON-COVID): a prospective cohort study. Lancet Respir Med. 2020;8(8):765-74. https://doi.org/10.1016/S2213-2600(20) 30268-X Epub 2020 Jun 19.

7. Kimmoun A, Roche S, Bridey C, Vanhuyse F, Fay R, Girerd N, et al. Prolonged prone positioning under VV-ECMO is safe and improves oxygenation and respiratory compliance. Ann Intensive Care. 2015;5(1):35. https://doi.org/10.1186/s13613-015-0078-4 Epub 2015 Nov 4.

8. Guervilly C, Hraiech S, Gariboldi V, Xeridat F, Dizier S, Toesca R, et al. Prone positioning during veno-venous extracorporeal membrane oxygenation for severe acute respiratory distress syndrome in adults. Minerva Anestesiol. 2014;80(3):307-13 https://www. minervamedica.it/en/journals/minerva-anestesiologica/article.php? cod=R02Y2014N03A0307.

9. Guérin C, Reignier J, Richard JC, Beuret P, Gacouin A, Boulain T, et al. Prone positioning in severe acute respiratory distress syndrome. N Engl J Med. 2013;368(23):2159-68. https://doi.org/10. 1056/NEJMoa1214103.

10. Rilinger J, Zotzmann V, Bemtgen X, Schumacher C, Biever PM, Duerschmied D, et al. Prone positioning in severe ARDS requiring extracorporeal membrane oxygenation. Crit Care. 2020;24(1):397. https://doi.org/10.1186/s13054-020-03110-2.

11. Franchineau G, Bréchot N, Hekimian G, Lebreton G, Bourcier S, Demondion $\mathrm{P}$, et al. Prone positioning monitored by electrical impedance tomography in patients with severe acute respiratory distress syndrome on veno-venous ECMO. Ann Intensive Care. 2020;10(1):12. https://doi.org/10.1186/s13613-020-0633-5.
12. Fanelli V, Ranieri VM. Mechanisms and clinical consequences of acute lung injury. Ann Am Thorac Soc. 2015;12(Supplement 1): S3-8.

13. Ferguson ND, Fan E, Camporota L, Antonelli M, Anzueto A, Beale $\mathrm{R}$, et al. The Berlin definition of ARDS: an expanded rationale, justification, and supplementary material. Intensive Care Med. 2012;38:1573-82

14. Datzmann T, Träger K. What about prognostic outcome parameters in patients with acute respiratory distress syndrome (ARDS) treated with veno-venous extracorporeal membrane oxygenation (VVECMO)? Thorac Dis. 2018;10(Suppl 17):S2057-61.

15. Combes A, Brodie D, Bartlett R, Brochard L, Brower R, Conrad S, et al. Position paper for the organization of extracorporeal membrane oxygenation programs for acute respiratory failure in adult patients. Am J Respir Crit Care Med. 2014;190:488-96.

16. Hoyler MM, Kumar S, Thalappillil R, White RS, Tam CW. VVECMO usage in ARDS due to COVID-19: Clinical, practical and ethical considerations. J Clin Anesth. 2020;65:109893. https://doi. org/10.1016/j.jclinane.2020.109893 Epub 2020 May 20.

17. Peek GJ, Mugford M, Tiruvoipati R, Wilson A, Allen E, Thalanany $\mathrm{MM}$, et al. Efficacy and economic assessment of conventional ventilatory support versus extracorporeal membrane oxygenation for severe adult respiratory failure (CESAR): a multicentre randomised controlled trial. Lancet. 2009;374:1351-63.

18. Combes A, Hajage D, Capellier G, Demoule A, Lavoue S, Guervilly C, et al. Extracorporeal membrane oxygenation for severe acute respiratory distress syndrome. N Engl J Med. 2018;378: 1965-75.

19. Investigators ANZEMOI, Davies A, Jones D, Bailey M, Beca J, Bellomo R, et al. Extracorporeal membrane oxygenation for 2009 influenza $\mathrm{A}(\mathrm{H} 1 \mathrm{~N} 1)$ acute respiratory distress syndrome. JAMA. 2009;302:1888-95.

20. Guérin C, Beuret P, Constantin JM, Bellani G, Garcia-Olivares P, Roca $\mathrm{O}$, et al. A prospective international observational prevalence study on prone positioning of ARDS patients: the APRONET (ARDS Prone Position Network) study. Intensive Care Med. 2018;44(1):22-37. https://doi.org/10.1007/s00134-017-4996-5 Epub 2017 Dec 7.

21. Guérin C, Albert RK, Beitler J, Gattinoni L, Jaber S, Marini JJ, et al. Prone position in ARDS patients: why, when, how and for whom. Intensive Care Med. 2020;46(12):2385-96. https://doi.org/10. 1007/s00134-020-06306-w.

22. Lindahl SGE. Using the prone position could help to combat the development of fast hypoxia in some patients with COVID-19. Acta Paediatr. 2020;109(8):1539-44. https://doi.org/10.1111/apa. 15382 Epub 2020 Jun 17.

23. Abroug F, Ouanes-Besbes L, Dachraoui F, Ouanes I, Brochard L. An updated study-level meta-analysis of randomised controlled trials on proning in ARDS and acute lung injury. Crit Care. 2011;15: R6 53.

24. McAuley DF, Giles S, Fichter H, Perkins GD, Gao F. What is the optimal duration of ventilation in the prone position in acute lung injury and acute respiratory distress syndrome? Intensive Care Med. 2002;28:414-8.

25. Scholten EL, Beitler JR, Prisk GK, Malhotra A. Treatment of ARDS With Prone Positioning. Chest. 2017;151(1):215-24. https://doi.org/10.1016/j.chest.2016.06.032 Epub 2016 Jul 8.

26. Guérin C, Reignier J, Richard JC, Beuret P, Gacouin A, Boulain T, et al. Prone positioning in severe acute respiratory distress syndrome. N Engl J Med. 2013;368:2159-68.

27. Abroug F, Ouanes-Besbes L, Elatrous S, Brochard L. The effect of prone positioning in acute respiratory distress syndrome or acute lung injury: a meta-analysis. areas of uncertainty and recommendations for research. Intensive Care Med. 2008;34:1002-11.

28. Iruvoipati R, Bangash M, Manktelow B, Peek GJ. Efficacy of prone ventilation in adult patients with acute respiratory failure: a meta- 
analysis. J Crit Care. 2008;23(1):101-10. https://doi.org/10.1016/j. jcrc.2007.09.003.

29. Mancebo J, Fernandez R, Blanch L. A multicenter trial of prolonged prone ventilation in severe acute respiratory distress syndrome. Am J Respir Crit Care Med. 2006;173:1233-9.

30. Koeckerling D, Barker J, Mudalige NL, Oyefeso O, Pan D, Pareek $\mathrm{M}$, et al. Awake prone positioning in COVID-19. Thorax. 2020;75(10):833-4. https://doi.org/10.1136/thoraxjnl-2020215133.

31. Culbreth RE, Goodfellow LT. Complications of prone positioning during extracorporeal membrane oxygenation for respiratory failure: a systematic review. Respir Care. 2016;61(2):249-54. https://doi.org/10.4187/respcare.03882.

32. Moore Z, Patton D, Avsar P, McEvoy NL, Curley G, Budri A, et al. Prevention of pressure ulcers among individuals cared for in the prone position: lessons for the COVID-19 emergency. J Wound Care. 2020;29(6):312-20. https://doi.org/10.12968/jowc.2020.29. 6.312 .

Publisher's Note Springer Nature remains neutral with regard to jurisdictional claims in published maps and institutional affiliations. 